This item was submitted to Loughborough's Research Repository by the author.

Items in Figshare are protected by copyright, with all rights reserved, unless otherwise indicated.

\title{
Institutional racism, whiteness and the under-representation of minorities in leadership positions in football in Europe
}

PLEASE CITE THE PUBLISHED VERSION

http://dx.doi.org/10.1080/14660970.2013.801262

\section{PUBLISHER}

Routledge (@ Taylor \& Francis)

VERSION

AM (Accepted Manuscript)

\section{PUBLISHER STATEMENT}

This work is made available according to the conditions of the Creative Commons Attribution-NonCommercialNoDerivatives 4.0 International (CC BY-NC-ND 4.0) licence. Full details of this licence are available at: https://creativecommons.org/licenses/by-nc-nd/4.0/

\section{LICENCE}

CC BY-NC-ND 4.0

\section{REPOSITORY RECORD}

Bradbury, Steven. 2019. "Institutional Racism, Whiteness and the Under-representation of Minorities in Leadership Positions in Football in Europe”. figshare. https://hdl.handle.net/2134/24548. 
Dr Steven Bradbury

Senior Research Associate and Lecturer in Young People and Sport

Institute of Youth Sport

School of Sport, Exercise and Health Sciences

Loughborough University

s.bradbury@lboro.ac.uk

Title:

Institutional racism, whiteness and the under-representation of minorities in leadership positions in football in Europe

\begin{abstract}
:
This article seeks to critically examine the relationship between processes and practices of institutional racism and the continued under -representation of minorities in leadership positions in football in Europe. In doing so, the article will begin by providing a marker for levels of minority representation in senior administrative and governance positions within professional football clubs and national governing bodies of football. The article will then draw on interviews with twenty key stakeholders drawn from thirteen different countries to examine the extent and ways in which practices of institutional racism have impacted disproportionately on limiting minority access to - and involvement in - the senior organisational tiers of the game. The article will argue that these practices of institutional racism are underpinned by patterns of white hegemonic privilege embedded within the pre-existing core structures of decision making bodies at the highest levels of football. Finally, the article will suggest ways through which to challenge and dismantle these practices of racially inflected institutional closure and patterns of white hegemonic privilege and improve the legitimacy and functioning of the sport across the continent.
\end{abstract}

\title{
Introduction:
}

The social and cultural arena of elite level football (and sports more broadly) is often held up in popular public and mediated discourse as an increasingly post-racial, meritocratic and egalitarian space where 'race' no longer matters and where racial inequalities are a thing of the past. Such assumptions draw heavily on the achievements of high profile minority footballers as evidence of the inclusivity of the sport and its capacity to offer opportunities for personal advancement and social mobility for minorities in ways which might be denied in other areas of public life. However, such assumptions largely overplay the extent to which access to and involvement in football at the highest level is free from wider social, economic, cultural, and organizational limits and pressures (Carrington 2010). This is especially the case in Europe, where wider political narratives around national identity and citizenship and the practical implementation of policies of multiculturalism, integration, assimilation or non-intervention impact strongly on the everyday lived experiences of minority populations in different ways across different nation-states. To this end, it can be argued that the development, organisation 
and practice of elite level football does not take place in a social, cultural or political vacuum, but, rather, it is reflective of and reflects back upon a series of historically inscribed and deeply racialised power relations embedded within the societies in which it takes place. Further, the sport remains a site in which the complex configuration of overt, culturally coded and more institutional forms of racism and discrimination impinge upon and are generated in and through its practice and encounters. It is also the case that there remain significant inconsistencies in levels of involvement in playing the game between different ethnic, cultural and religious minorities, and a more general under-representation of all minorities as coaches and in leadership positions within the sport. These skewed patterns of minority representation in football have arguably positioned minorities as 'fit for doing' but not 'fit for organizing' the sport and support the assertion that 'the assimilation of black people within the national imagination as sports heroes need not in any way be incongruent with access to the centres of decision making and institutional power' (Back et al 2001:4).

In examining the relationship between minority under-representation, institutional racism, and hegemonic white privilege in leadership positions in football, this article will draw on original empirical data collected as part of a UEFA funded research study examining issues of structural discrimination in football in Europe (Bradbury et al 2011). In particular, the article will draw on extensive semi-structured interviews conducted with twenty sports academics, fan activists, NGO's, policy makers and senior administrative staff at national football federations and at UEFA drawn from thirteen countries across Europe. These countries include; England, Northern Ireland, Republic of Ireland, France, Norway, Poland, Hungary, Germany, Austria, Switzerland, Spain, Malta, and the Netherlands. All interviews were conducted by the author and interviewees were identified in consultation with UEFA and the Football Against Racism in Europe (FARE) network: a non-governmental organization which aims to tackle discrimination in football and to use the sport as a vehicle to promote integration and empower marginalized groups. Each interview lasted for between sixty and ninety minutes and afforded opportunities for interviewees to draw on their own extensive experiences of football and equality issues, and to define and discuss issues relating to institutional racism and minority under-representation in leadership positions in football within their own terms of reference.

Further, it is important to note that given the broad geographical focus of this research, the term 'minority' is used here as a broad descriptive marker to refer to ethnically, culturally, religiously and sub-nationally distinct population's resident within nation state boundaries of Europe. This broad conceptualization of minorities includes both second and third generational 'settled' minority communities and more recent economic migrants and asylum and refugee groups drawn from a range of European and non-European backgrounds who presently reside in countries in which they make up a numerical minority. This definition of minorities is also premised on the recognition that minority status is both objectively ascribed (by the dominant society) and subjectively applied (by minority groups) as a means marking out ethnic, cultural, religious and sub-national difference. Whilst these differences can be applied positively as a marker of cultural identity and group solidarity, they are much more often applied negatively as a basis for abuse, hostility and discrimination. This is especially the case within football where 
patterns of overt and more institutional forms of racism and discrimination continue to shape the experiences of minorities and limit the parameters of minority involvement in the game.

\section{Previous research on institutional racism and football:}

Whilst over the last thirty years there has developed a steadily growing body of academic and policy based research examining issues of overt racism in football in Europe, there has until relatively recently been a much more limited focus on examining issues of institutional racism in the sport. Where such focus exists, it has largely sought to examine the ways in which processes and practices of institutional racism have impacted negatively in limiting the participation of minorities in the game as players. For example, a number of UK based studies have alluded to a series of relatively 'closed' operational approaches to youth talent identification at professional clubs which have historically failed to incorporate a range of sites and local settings in which young minority players are present (Bains and Patel 1996, Bains 2005, Football Task Force 1998, CRE 2004). To this end, the work of Burdsey $(2004,2007)$ is especially instructive in illustrating the ways in which these practices of institutional closure are underpinned by a series of cultural misconceptions which portray South Asian cultures as static, falsely homogeneous and culturally disinterested in football. Similar processes of cultural stereotyping which have constructed young black players as 'difficult', 'bad tempered' and 'lacking in social etiquette' have been evidenced within professional club youth academies in Denmark (Agergaard and Sorenson 2009). These studies also suggest that within such 'limited conditions of equality' young minority players are expected to exercise much greater adaptation to the social and cultural mores of dominant majority populations at clubs and to 'leave their cultural identity at the door'. These findings chime strongly with the work of King (2004a, 2004b) who asserts that the upwardly mobile career trajectories of minority players and their transition from playing into coaching are premised on the successful negotiation of dialogic, non-verbal and ritualized processes through which the attainment of 'cultural passports' and contingent inclusions are granted or withheld within the normative white spaces that define the football workplace.

These processes and practices of institutional racism are not restricted to the professional game. A number of studies have identified formal and informal processes of institutional racism in amateur football in Europe. For example, two recently published reports have each referenced examples of institutional racism embedded within the conjunctive relationship between restrictive national political models of citizenship and organizational practices enacted by national governing bodies of football and sports in Europe (ECRI 2008, EU/FRA 2011). In both cases, these reports allude to administrative and legislative restrictions which limit participation in organized football (and other sports) amongst 'non-citizens' drawn from new and established minority backgrounds in one-third of EU countries. The EU FRA report also cites examples of discriminatory treatment in the allocation of training and match-day facilities for minority football clubs in countries such as Austria, Germany, Finland and Luxembourg. A number of UK based studies have also alluded to relatively hidden forms of institutional racism embedded within the everyday operations of amateur football clubs, and at regional and national football federations. For example, the ethnographic studies of Burdsey $(2006,2009)$, Bradbury $(2010$, 
2011a) and Campbell (2011) all identify subtly enacted patterns of racial closure at pre-existing (white) amateur clubs which limited the initial involvement of first and second generation minority players in England in the 1960s, 1970s and 1980s. These findings have been echoed by research studies in the Netherlands and Denmark which have examined the lack of throughput of minority players from recreational 'street football' to more structured participation in organized amateur football settings, and with regard to the exclusion of marginalized Roma populations from mainstream amateur clubs in Central and Eastern Europe (Halm 2005, Agergaard and Sorenson 2009, Bradbury et al 2011). Research studies in the UK and Sweden have also drawn attention to unequal disciplinary procedures enacted against minority football clubs in organized amateur football leagues and competitions, and an apparent reluctance of football authorities to acknowledge and deal swiftly and effectively with incidents of racist abuse targeting minority players (Burdsey 2009, Andersson 2009, and Bradbury 2011).

Much less academic attention has been paid to the relationship between practices of institutional racism and minority under-representation in coaching and leadership positions in football. Where studies do exist they have drawn attention to the 'open secret' of the underrepresentation of minorities and identified a series of structural and cultural filters which have impacted negatively on limiting minority access to these tiers of the sport. For example, research undertaken by Bradbury et al (2011) has argued that football club owners have internalized a series of historically inscribed and deeply racialised stereotypes which equate minority coaches with 'physicality over intellect', 'emotional' and 'attitudinal' deficiencies and 'uncertainty' and 'risk'. Further, it is argued that club owners have traditionally exhibited little awareness of the qualifications, experience, and competence of minority coaches and tend to recruit coaches from a limited 'knowledge bank' of already known applicants from within the dominant (white) social and cultural networks of the football industry. UK based studies also suggest some significant parity between processes of coaching and managerial recruitment and the recruitment of senior administrative staff at professional football clubs. For example, research in England has reported that only $36 \%$ of professional football clubs always publicly advertise for senior administration positions, and that $79 \%$ of professional clubs continue to recruit senior administrators through relatively informal mechanisms, including by 'personal recommendation' and through 'word of mouth' networks (Bradbury 2001, CRE 2004). Bradbury et al (2011) also suggest similar patterns of patronage and sponsored mobility are evident within the hierarchical pyramid structures of football federations tasked with governance of football at the regional, national and international level. Whilst these practices of recruitment and reward are often presented as being relatively benign and might be unconscious and unintentional, they nonetheless gravitate against the inclusion of minorities who are positioned outside of the dominant (white) insider networks of football. For some authors, the concept, practices and outcomes of institutional racism in football (and in sport more broadly) are underpinned by the 'invisible centrality of whiteness' embedded within the senior organizational tiers of the game. From these more critical perspectives, the power of whiteness as a process is in its ability to frame white privilege and related social and economic advantages as the cultural norm and preclude any recognition of the beneficial membership of dominant social and cultural networks and the profits of mutual acquaintance. Further, it is argued that it is the unremarked, everyday taken for granted-ness of whiteness which has enabled the games 
key power-brokers to maintain their powerful position as 'inside' and 'included', whilst minorities remain 'outside' and 'excluded' from key decision making positions within powerful administrative and legislative bodies within the sport. To this end, Hylton has argued that these deeply racialised power relations and patterns of white privilege enable racism to be effortlessly reproduced and perpetuated and for the dominant white hegemonic structures of the sport to remain unchallenged and unchanged (Hylton 2009).

\section{The findings:}

\section{The open secret of minority under-representation in leadership in football:}

Since the 1950s and 1960s there have been a steady increase and more recent acceleration of the ethnic, cultural, and religious diversity within the national populations of many European countries. This is especially case in many Western European countries where in-migration trajectories have been underscored by the settlement of non-European populations drawn from former colonies, such as South Asian and African-Caribbean populations in the UK, and sub-Saharan and North African populations in France, Portugal and the Netherlands. Whilst the pace of in-migration from former colonial territories has slowed over time, processes of family re-union and the higher fertility rates of many families of non-European backgrounds has meant that there is now a firmly established cohort of second and third generation minority populations in many Western European countries. Since the 1990s, non-European in-migration trajectories to countries such as the UK, France, Netherlands and Sweden have been more strongly linked to the growth in asylum seekers and refugees fleeing political persecution and armed conflicts in the Middle East, Asia and Africa (Bloch and Levy 1999, Pillai et al 2006). Following the incorporation of the Schengen agreement into European Union law in 1997 and the expansion of EU member states from the mid-2000s onwards, the continent has also experienced significant population movements across national borders amongst cohorts drawn from European origin. Conversely, many post-communist countries in Central and Eastern Europe appear relatively culturally homogeneous with few 'visible' ethnic minorities, although the presence of national and religious minorities arguably cuts across east-west regional divides and the political construction of nation state boundaries.

Over the past twenty years the higher echelons of men's professional football in Europe has also become characterized by the increasing ethnic, cultural and religious diversity of its playing staff. This is especially the case with reference to players drawn from second and third generation established Black Caribbean and Black African populations at clubs in Western European countries with former colonial histories. For example, research studies suggest that 'home-grown' black players have consistently accounted for around $15 \%$ of all players in the English and Dutch leagues since the mid 1990's (Bradbury 2001, Hermes 2005). There is also a reported (albeit, highly localized) over-representation of, mainly, black, minorities at professional club youth academies in England, France, Belgium and Portugal (Bradbury et al 2011). The increasing cultural diversity of players within professional football in Europe has also been informed by the tendency of elite professional clubs to have broadened player recruitment processes in recent years to include new global markets. This has led to an increase 
in the global migration flows of 'foreign' or 'expatriate migrant' footballers across national and continental borders (Lanfranchi and Taylor 2001, Poli 2006, Darby 2007). For example, during the 2008-2009 football season 32.7\% of players at clubs in Europe's Premier Leagues were 'expatriate migrant' players, including more than $50 \%$ of players in Portugal, Belgium, Greece and England. In the latter case, English Premier League clubs featured players from more than fifty different nationalities drawn from six different continents (Besson et al 2010).

The growing visibility of 'home grown' minority players coupled with increased global migratory flows of players has undoubtedly contributed to the rich cultural mix of players in the top domestic leagues in Europe. However, the focus on high profile minority football players tends to provide a skewed picture of events and is not a valid indicator of minority representation across different tiers of the game in Europe. For example, a number of UK based studies have alluded to the consistently low levels of second and third generation South Asian heritage players at professional club youth academies and as adult professional players (Bains and Patel 1996, Bains 2005, Burdsey 2004, 2007). Similarly, studies in the Netherlands and Denmark have referenced the marked absence of Turkish, Moroccan and Somali heritage players at clubs in contrast to their strong levels of active participation within the organized amateur game and their significant numerical presence within wider national populations (Van Sterkenburg et al 2005, Agergaard and Sorenson 2009).

Further, despite their longstanding involvement in the game in many Western European countries, there remains a minimal throughput of minority players into coaching and team management positions at men's professional clubs throughout Europe. For example, there have been only a handful of black managers at professional clubs in England and at the time of writing only three of the 92 professional club managers in England is black. Further, few minority coaches are employed in 'behind the scenes' coaching support infrastructures at professional clubs or at national or regional football federations across Europe (Bradbury 2011 et al). Where small breakthroughs into coaching and management have occurred in countries such as England, France and the Netherlands, minority coaches tend to have had a strong prior playing connection with specific clubs or to have been high profile international players. It is also the case that the increasing tendency amongst top clubs to recruit 'foreign' managers has done little to disrupt the demographic homogeneity of the existing football workforce: these new coaching and managerial imports remain almost exclusively white.

Relatively few sports policy bodies, national sports federations or academic research studies have focused on examining the levels of minority representation in leadership positions in sports. This is especially the case in football where there is little available empirical data collected by UEFA, national federations, leagues or clubs to this end. It is probably the case that data collection procedures of this kind have been afforded little priority by those charged with the administration and governance of the game throughout Europe. It is likely too, that in some cases, the lack of empirical evidence on this score reflects a general apathy and marked defensiveness to collecting data of this kind. This is the probably the case in countries in which the demographic make-up of national populations is perceived to be culturally homogeneous and/or where issues of racial equality feature relatively low on the political agenda. It is, of 
course, also the case, that some national football federations in Europe have few financial resources and limited infrastructure within which to obtain data of this kind. Where studies do exist they indicate a broad consensus of opinion which suggests the marked absence of minorities in leadership positions in football across a range of national contexts (Long et al 2009, EU/FRA 2011, and Bradbury et al 2011). This seems especially marked amongst the senior administrative tiers and executive committee level of national football federations. For example, UK based studies have indicated that less than $1 \%$ of senior officials at national and regional football associations are from minority backgrounds (Bradbury 2001, CRE 2004, and Lusted 2009). These wider racialised inequities seem fairly consistent across Europe. For example, all twenty interviewees within this study intimated that figures for minority representation in the senior administrative and governance tiers of national federations were unlikely to exceed $1 \%$ in total. They also suggested that the demographic make-up of executive committees and expert panels at UEFA were predominantly drawn from majority populations within their respective countries. This is unsurprising given the pyramidal structure of Europe's football governing body and the processes of patronage, nomination and selection for UEFA executive committee level representation enacted at demographically 'closed' national federations. Similarly, interviewees reported estimated figures for minority representation in leadership positions at professional clubs in Europe of between $0 \%$ and $3 \%$ : figures borne out by similar research undertaken by the European Union Federal Rights Agency (EU/FRA 2011). These figures seem especially low given the cultural diversity of many national populations in Western Europe, where between $10 \%$ and $20 \%$ of citizens are from minority backgrounds and where minorities have a longstanding connection with the sport as players. This is especially the case in England where studies have indicated that less than one-third of professional clubs employ any minority 'white collar' staff and where only $1 \%$ of all senior administrative staff are drawn from minority backgrounds (Football Task Force 1998, Bradbury 2001, CRE 2004). To this end, available empirical data and the comments of key stakeholders suggest some consensus in identifying the 'open secret' of minority under-representation in key decision making positions in football across the continent.

\section{Institutional racism and whiteness: It's not what you know, it's who you know}

In this section, the article will draw on extensive interview data and wider academic analysis to identify and examine the ways in which practices of institutional racism have limited minority access to and involvement in the senior organizational tiers of football. In the first instance, a number of interviewees sought to explain the absence of minorities in leadership positions in the game with reference to wider societal inequalities which have limited opportunities for the social mobility of minority populations more broadly. These assertions are supported to some extent by a significant body of academic and policy based research which has highlighted the more general under-representation of minorities in key decision making positions across a range of social, cultural, economic and political institutions at the national level across Europe. Whilst research of this kind has differed in its focus, scope and content, there has been a broad analytical consensus which equates patterns of minority under-representation with inequalities of access to social, economic, and cultural resources and practices of overt and institutionalized forms of racism and discrimination (Coussey 2002, Armstrong et al, 2005, COE/ECRI 2006, 2010, 
EC 2008, Berman and Paradies 2010). These studies suggest that such unequal patterns of social relations are exacerbated by key factors such as the socio-historical specificities of inmigration trajectories, the cultural and religious distinctiveness of some minority groups, and the limited educational and language skills of many first generation migrants (Niesson 2000, Anthias 2001, Miles 2003, Modood 2005, and ECRI 2006). However, they also suggest that even in countries which feature a range of more established and relatively integrated second and third generation minority populations, there is evidenced examples of continued structural discrimination, sustained social and economic disadvantage, and shared experiences of social exclusion and marginalization between different minority groups. This has led to the uneven residential spread of minority populations in deprived urban locales, or, as in the case of Roma, in rural areas experiencing high levels of territorial and infrastructural isolation.

For a number of interviewees, these broader societal inequalities were perceived to have had a significant knock-on effect in limiting the potential of minorities to access key 'white collar' positions in a range of public and private sector organizations, including football clubs. Further, these interviewees suggested that for many professional clubs based in predominantly 'white' locales, especially more rural clubs at the lower end of the professional spectrum, there may be a limited 'diversity pool' of suitably qualified local minority workers for senior administrative employment positions. This was considered by interviewees to be especially the case where medium sized and smaller professional clubs were situated in cities and towns characterized by their cultural homogeneity and where there were few established or new minority populations with relevant educational qualifications commensurate with the requirements of work of this kind.

Relatedly, a number of interviewees also drew attention to the intersectionality between ethnicity and the generational distribution of leadership positions at professional football clubs and in football governance. That is, some interviewees suggested that these positions tended to be reserved for older applicants and that this was likely to favour white applicants by virtue of the statistically older age distribution of majority populations in some countries in contrast to generally younger minority populations. Similarly, interviewees suggested these generational and racialised distributional patterns of senior administrative and governance employment in football were comparable with similarly tiered occupational realms in the wider business sector. For example:

'It's partly the same reason that the members of the government or the members of the boards of PLC's are in the same way generally older and generally white. It's more ethnic minorities slowly, but it still doesn't represent at all society at large. This is not a justification, it's an explanation, that football is simply reflecting society at large' (Interviewee, England)

'I think that there's an acceleration of the integration of males from ethnic minorities in society, and in football. This is especially the case in Western Europe. So I would not be surprised if 20 years from now you will see a lot of different cultures 
in administration, in places like England, France, Germany, who have come from ethnic minorities' (Interviewee, France)

It is, of course, the case, that analysis of issues of minority under-representation in leadership positions in football cannot be divorced from wider structural, cultural and demographic factors which position minority's disadvantageously in local societal relations and within local labour markets. It is probably also the case that the increasing visibility and (partial) social mobility of minorities in society and in professional football as players is in part reflective of the gradual societal and sporting integration of some minority groups in some more culturally diverse countries in Europe. However, the 'inevitably of social change' and 'gradual march towards integration' narratives featured in the comments above arguably overplay and idealize the meritocratic and inclusive potential of football. Further, they simultaneously position football as being both subject to - and yet simultaneously separate from - those practices of overt, culturally coded and more institutional forms of racism and discrimination which impact negatively on the everyday experiences of minority populations. To this end, and a little more critically, a number of interviewees suggested that rather than being a separate, more inclusive, space in which the social mobility of minorities was likely to gather momentum over time, football was considered to fare much less favourably with comparable governmental or business sector organizations in this respect. This was considered to be especially the case in a number of more culturally diverse countries in Western Europe in which some generationally established minority populations have engendered an increasing visibility in other echelons of social, economic and political life:

'Now obviously it's even worse in football than in society at large because there are even fewer ethnic minorities in top positions than in business or in politics in general. That suggests that it's even harder for ethnic minorities to succeed in football' (Interviewee, Germany)

In explaining these racialised disparities within leadership positions in football, a number of interviewees referred to a series of relatively 'closed' practices of recruitment within the senior administrative tiers of professional football clubs across Europe. These narratives featured some significant comparability with prior survey based research undertaken in England which alluded to the lack of public advertising of senior administrative positions and the tendency towards recruiting through informal word of mouth networks and personal recommendation (Bradbury 2001, CRE 2004). Interviewees in the Netherlands and England comment further in this respect:

'Why are we not seeing minorities coming into administration? I'm sure again the recruitment processes are limited, in terms of the way that people actually get jobs. Are jobs advertised in what you would expect to be an open and transparent way? Not always, probably' (Interviewee: Netherlands) 
'The reason is simple. How can minorities get these jobs, or even apply for these jobs, if they don't even know that they exist, or that there is not a proper process for them to go through to even be considered for these jobs' (Interviewee: Germany)

The comments above suggest some significant parity between the processes of recruitment of senior administrators and the recruitment of team managers, coaches and players at professional clubs. In particular, that they are often targeted or 'head hunted' from a preexisting (albeit demographically limited) 'knowledge bank' of potential candidates. The broader inference here is that these mechanisms of 'white collar' recruitment gravitate against the inclusion of potential applicants drawn from minority populations who are outside of the dominant (white) social and cultural networks of which typify the football industry. Further, it is arguably the case that despite the broadly rhetorical support of many professional clubs for national and international anti-discrimination campaigns in football, there is little evidence to suggest the practical implementation of practices of equality in terms of recruitment to the senior organizational tiers of club infrastructures. For example, research undertaken in the UK has indicated that despite 'signing up' to officially endorsed equality programmes in football, few professional clubs have adhered to or have fully operationalized the stated commitments of equal and fair treatment enshrined in official equal opportunities policies, where such policy documents exist in any real sense at all (Bradbury and Williams 2006, Bradbury 2011b).

A number of interviewees suggested that similar patterns of racial closure are evident within the hierarchical pyramid structures of football federations tasked with governance of football at a regional, national and European level. Initial access to executive decision making committees at federation level are often premised on the sponsored mobility, patronage and personal recommendation of more senior figures within these governing bodies. These 'promotions' are commonly perceived as a reward for individuals who have exhibited long standing paid and/or voluntary services to football in their regions or at a national level. Given the historically inscribed power relations embedded within the game and the culturally homogeneous demographic of older white males within existing football governance infrastructures, it is hardly unsurprising that minority populations continue to be marginalized from accessing these insider networks. These assertions were strongly echoed by interviewees who drew clear and specific linkages between these embedded practices of institutional racism and the continued under-representation of minorities from leadership positions within the sport. For example:

'If it were based on people being appointed for their skills, you would see a lot more minorities. But with the pyramid or democratic way in which those instances are designated, there's no chance'. (Interviewee: Austria)

'The structural and organizational culture of something like the English FA in terms of our constitution and processes, that's a real blocker, because our participation base has been traditionally white and male and that's not really changing in the governance aspect of the game'.(Interviewee: England) 
'One of the reasons for the under-representation of minorities is it is a first past the post system for getting on in organizations like football associations and so on. You can have ten or twenty people and the one who's more likely to get the position as president or chairman or the secretary or whatever it is, is the one who is like the median of the group, which, in most cases, is likely to be an older white male'. (Interviewee: Switzerland)

The processes and practices of institutional racism referred to above are arguably underpinned by patterns of white hegemonic privilege embedded within the pre-existing core structures and decision making bodies at professional football clubs and within football governance. Giroux has argued that:

'Analyzing whiteness as a central element of racial politics becomes useful in exploring how whiteness as a cultural practice promotes race based hierarchies, and how white racial identity structures the struggle over cultural and political resources' (Giroux 1997: 295).

This conceptualization provides a useful starting point from which to examine the ways in which the invisibility, normativity and centrality of whiteness has shaped and maintained the status quo of racialised power relations and white privilege within the senior organizational tiers of football at the highest level. This can be evidenced through those institutionally closed practices of recruitment, selection and promotion which favour individuals drawn from recognizable backgrounds with similar (white) cultural norms, values and behaviours to the games key power brokers. The interviewees below articulate these themes further:

'Well, they are the same group as the one which recruit's new members. They recruit each other. It's really the old white men's network. When they look for new members, they make the list with criteria and they always make the criteria which they fit themselves, so that's the way it works. They think that it's good, because they all look alike and they all think alike and therefore most of the time they agree with each other very quickly' (Interviewee: Malta)

'I think it's 'like for like' people. People do that because they think they're going to recruit someone who will help them achieve their objectives more' (Interviewee: Hungary)

It's an old boys club. Because the clubs, the leagues, the national associations, the regional associations, the local associations, are full of older white males. It's a closed system. You elect people who basically, you know, you trust. Who share the same values as you do, who come from the same background'. (Interviewee: Germany)

Whilst the comments above reflect to some extent the unintentional and indirect nature of institutional racism and the inevitability of its inequitable outcomes, a little more critically a 
number of interviewees suggested some more deeply embedded 'cultures of resistance' to more equitable change amongst the games key power brokers. For example:

'We've seen a lot of resistance by a lot of football administrators. They don't like to talk about the issue. They don't like people to examine the problem. Because they understand that if the issue comes to the fore, then it may have to be addressed and a lot of them don't want that' (Interviewee, France)

The fact is, I'm sure you'll find that in every business group, if you have power, why should you welcome other individuals. There is that basic solidarity that we stay amongst ourselves, it's much more comfortable. I don't know many groups that open up in this spontaneous way. Unless they feel that they will get something out of it. And certainly that's not the feeling right now' (Interviewee, Switzerland)

'What you find in football is a very conservative mentality and change is a very big word. People like the status quo. Change is a very difficult thing to implement and forced change is probably more so because it's always going to be resisted at the top, where they feel like they're going to lose something along the way' (Interviewee, Northern Ireland)

The comments above chime strongly with the assertions of a number of academic authors who have sought to 'unpack' the reasons for the apparent slow pace of change and limited response of governing bodies of football (and sports more broadly) to engage with and implement a range of initiatives designed to encourage best racial equality practice at an organizational level (Long 2000, Long and Hylton 2002, Long et al 2005, Long and Spracklen 2011, Bradbury and Williams 2006, Lusted 2009, 2011). In the context of this study, it can be argued that the apparent resistance to 'opening up' the structures at football clubs and within football governance are to some extent reflective of the dominant political paradigms in certain nation states. This is arguably especially the case in countries which exhibit rigid models of national identity and citizenship and where there is a marked defensiveness and a general deprioritization of governmental or sports policy interventions designed to address of minority discrimination. To this end, in many ethnically and culturally polarized nation states across Europe where attitudes to 'race' have been much less malleable over time and where there exists a deeply embedded cultural resistance to the inclusion of minorities in local social relations, the likelihood of success in enabling more equitable access to the organizational tiers of football seems markedly lessened. It is probably also the case that the 'cultures of resistance' described above might also indicate a more general lack of 'problem awareness' or nonacknowledgement of the concept, practice, and outcomes of institutional racism and other forms of discrimination and represent a reactionary response to perceived personal criticisms on this score. This latter assertion is supported by two recent reports examining racial discrimination in sport in Europe, both of which draw attention to the apparent lack of awareness and denial of the existence of institutional racism and identify a marked lack of commitment amongst sports federations to address this phenomenon (ECRI 2008, EU/FRA 2011). On a much smaller scale, the work of Lusted in the UK $(2009,2011)$ is similarly 
instructive in identifying the traditional modus operandi of regional football governance and the distinctly conservative and colonialist ideologies of largely older white males who occupy powerful positions within this voluntary and relatively autonomous governance infrastructure. Lusted argues that the deeply embedded hegemonic whiteness and racialised power-base within amateur football governance enables a series of culturally defensive and protectionist rather than progressive and reformist philosophies and practices to be sustained over time.

It is argued here that the apparent normativity and privilege of whiteness inherent within the senior organizational tiers of football affords opportunities for key power brokers within the game to define social problems such as racial discrimination from a culturally hegemonic position of power and dominance which negate any sense of inward gaze or critical selfreflection. From this empowered position, minority under-representation in leadership positions in football becomes conceptualized as resulting from wider societal exclusions or as being informed by the negatively perceived cultural properties of minority groups, rather than being shaped and maintained by the everyday practices embedded within the organizations within which dominant groups have prospered. Finally, it is also likely that in some cases this resistance to more equitable change is simply reflective of a general reluctance to surrender accrued rewards and decision making powers at the personal level. As Hylton has argued 'racism is inescapably related to power and those with power are reluctant to give it up' (Hylton 2009:10).

\section{Challenging institutional racism and whiteness: positive actions and equality of outcomes}

In this final section, the article will draw on interviewee narratives and wider academic analysis to outline the reasoning for and ways in which to challenge practices of institutional racism and patterns of white hegemonic privilege which have sustained the status quo of racialised power relations in leadership positions in football in Europe. These debates have gathered momentum in recent years and have helped to raise awareness and force issues relating to minority underrepresentation in the wider football workplace onto the political agenda at the highest levels of the governance of the sport. For example, in 2001 the FIFA Buenos Aires Resolution against Racism officially endorsed action to address inequalities within the organization of football, and explicitly encouraged:

'All football bodies at all levels to ensure racial equality in the employment, appointment and election of individuals in all areas of activity and to work with ethnic groups to involve them more closely in football activities'

Similarly, the UEFA guide to 'tackling racism in club football' (2006) refers to the 'lack of equal representation of minorities in the game' and offers a broad definition of racism in football which draws parallels with the commonly cited definition of institutional racism as outlined in the UK MacPherson report (1999). It states that racism:

'Can occur intentionally, or through a lack of understanding and ignorance, it may manifest itself openly or covertly. It occurs at all levels of an industry or 
organization. Within football it may range from fans hurling racial abuse or to exclusionary practices by governing bodies at all levels, clubs or other partners of the game'

Further, in January 2011, UEFA hosted the first ever seminar on institutional discrimination in football in Amsterdam which was attended by around 80 delegates including senior officials from UEFA and nine different national football federations as well as sports academics, NGO's and fan activists from the FARE network. The seminar provided opportunities for awareness raising, dialogue, and sharing of models of best practice, however, the extent to which federation based attendees fully understood, accepted and have since expressed any sustained commitment to tackling the issues of institutional discrimination remains a moot point.

Nonetheless, central to ongoing efforts to challenge institutional racism and promote the more equitable participation of minorities in leadership positions in football is the belief that cultural diversity is a positive resource which should be recognized, developed and utilized to the benefits of individuals and organizations. These models of thought are most strongly aligned with countries in Europe which have successfully pursued multiculturalist and integrationist approaches to 'managing diversity' and which seek to promote intercultural exchange and the leveling of barriers of association. For a number of interviewees, increased cultural diversity within the senior organizational tiers of professional clubs and football governing bodies was considered to have significant potential benefits for minorities and for the sport. For example, in terms of harnessing the previously unused, under-valued and under-developed talents of minorities, and 'freshening up' and aligning more strongly the styles and outlook of leadership with the increasingly corporate impulses of the modern game. Further, interviewees suggested that increased cultural diversity would add value to football organizations in better enabling them to connect with the increasingly heterogeneous populations of the societies in which they are situated. For example:

'It's about recognizing people from diverse backgrounds, there's a fair possibility that a lot of them have a lot of really good skills. In addition they may have insights and knowledge of how things could be improved, so it's a valuable source that we should be tapping into' (Interviewee, Norway)

'Well, the only way that I think you're going to address these issues is the business model. It's the aspects of, "How do you run a football club efficiently, as a business, if you don't do it in the context of enabling yourself to access the best of people from all backgrounds?' (Interviewee, Switzerland)

'I think there are many extremely good examples in the corporate world where diversity of the workforce generates excellent results. It is there and it is performance based. I am convinced that diversity is a value' (Interviewee, France)

A key component of establishing more culturally diverse organizations has been through the implementation of practices of 'positive action', incorporating methods such as target setting, 
co-option and quotas. This approach and its methods has gathered pace in recent years across a range of nation states in Europe, especially those characterized by more multiculturalist and integrationist models of political thought. Broadly speaking, positive action approaches attempt to address the apparent disjuncture between equality of opportunities and (in)equality of outcomes experienced by minority populations in all areas of social, economic and political life. In doing so, they seek to move beyond those 'colour blind' neutral criteria approaches to recruitment which are perceived to contribute to, rather than sufficiently redress, patterns of minority under-representation. Further, they explicitly recognize and attempt to counter a series of institutionally embedded processes and practices of racial discrimination and challenge those white hegemonic power relations which contribute to the status quo of inequitable social relations. To this end, a number of interviewees suggested that positive action approaches might have a particular resonance as mechanism through which to address some residual patterns of institutional closure evidenced within the elite echelons of football governance. For example:

'We might argue that there are processes of structural discrimination in the neutral criteria idea of football governance, which doesn't look beyond people recruiting like themselves. I think you can change this, if you change the recruitment system a little bit. People have to see that you miss some talent which can be very useful for your organization' (Interviewee, Austria)

'Sometimes you have to treat people differently to make them more equal, to create an equal situation for them. This is the case in football at the highest level. The only thing that can really work is quotas. You have to force open the structures if it is not going to open up on a voluntary basis of its own accord' (Interviewee, Germany)

Further, a number of interviewees argued that the implementation of the practice of positive action and its methods might add significant practical and cultural value to the functioning and legitimacy of national football federations and at UEFA, and encourage a more progressive and inclusionary vision of the game than has been the case in the past. The interviewee below comments further in this respect and outlines the collaborative process through which such actions might be enacted:

'The more that we can have people being brave in positions of leadership and power and influence, actually opening up these opportunities, then the more the conversations will take place. Then below that, obviously that's at that kind of level which is a bit visionary and inspirational, but you've got to have positive actions in place, haven't you? You've got to actually do something that makes a difference so that we're not in ten years' time having that same conversation. You can't do that unless you get all the parties round the table and working collaboratively on it' (Interviewee, Switzerland)

Whilst the positive action approaches referred to above offer a very direct and immediate solution to increasing the representation of minorities in leadership positions in football, the 
implementation and success of such approaches is likely to be greatly enhanced if it is delivered as part of a more holistic package of educational, policy orientated and legislative action. This more integrative approach might in the first instance include a strong emphasis on developing and delivering an industry standard programme of cultural awareness and anti-discrimination training which specifically targets senior administrators, directors and executive committee members at professional clubs and in football governance. Whilst training of this kind might seek to promote the value and benefits of cultural diversity in football, it should also feature a strong emphasis on encouraging, enabling and enforcing professional clubs and the games ruling bodies to adhere to national and European equalities legislation with particular regard to employment practice. As Hylton has argued where the adherence to such legislation has been enforced by government departments in the UK, there has been at least some progress in pushing sports governing bodies towards embedding and evidencing commitment to tackle racism and promote racial equality at all tiers of their respective sports (Hylton 2009). Further, UEFA as Europe's governing body of football should play a central role in the co-ordination and implementation of such measures and work in closely in collaboration with key partner organizations such as the FARE network and relevant bodies within the European Union and the Council of Europe to this end. Finally, it can be argued that the legitimacy of UEFA in leading work of this kind would be greatly enhanced by engaging in meaningful and concerted efforts to review and amend a series of inherently discriminatory practices embedded within its own organizational infrastructure. Not least of all, with reference to the institutionally closed system of patronage, sponsored mobility and reward which underpins selection to decision making committees at UEFA and which has helped maintain the structural and cultural dominance of white men in the most powerful positions in football in Europe. Here the implementation of positive action measures such as target setting, co-option and quotas would significantly help to 'open up' access to suitably qualified candidates from minority backgrounds and other traditionally under-represented groups such as women. In doing so, UEFA would also set a clear example of good equality practice to the football nations of Europe which could encourage national federations to follow suit and have positive and far-reaching ramifications for the way in which the sport is governed and by whom across the continent. We conclude here with the words of one interviewee whose analogous description of the impact of such a top down approach to enabling social change has particular resonance here. He commented 'it's much easier to break a glass ceiling by stamping down on it from above, than it is to punch it through from below'. We would simply add, is UEFA willing to take that step? 


\section{References}

Agergaard, S., and Sorenson, J.K. (2009) 'The dream of social mobility: ethnic minority players in Danish football clubs', Soccer and Society. Vol 10 (6) 766-780

Anderson, T. (2009) 'Immigrant teams in Sweden and the case of Assyriska FF', Soccer and Society. Vol 10. 398-417

Anthias, F. (2001) 'New hybridities, old concepts: the limits of culture', Ethnic and Racial Studies, 24, 4: 619-41.

Armstrong, J. \& Ng, R. (2005) Deconstructing race, deconstructing racism in J. Lee \& J. Lutz (eds) Situating 'Race' and Racisms in Space and Time and Theory: critical essays for activists and scholars (Montreal: McGill University Press, p30-45).

Back, L,. Crabbe, T., Solomos, J. (2001) The Changing Face of Football: Racism, identity and multiculture in the English game Oxford: Berg

Bains J. with Patel R. (1996) Asians can't play football. Birmingham: Asian Social Development Agency.

Bains, J. (2005) Asians can play football: Another wasted decade. University of Leicester

Berman, G. \& Paradies, Y. (2010) 'Racism, disadvantage and multiculturalism: towards effective antiracist praxis', Ethnic and Racial Studies, 33, 2: 214-32.

Besson, R., Poli, R. \& Ravenel, L. (2010) Demographic study of footballers in Europe 2010. Neuchatel: Professional Football Players Observatory

Bradbury, S., (2001) The New Football Communities: A Survey of Professional Football Clubs on Issues of Community, Ethnicity and Social Inclusion. SNCCFR

Bradbury, S. and Williams, J. (2006). 'New Labour, racism and 'new' football in England', Patterns of Prejudice, Vol 40, No 1, pp 61-82

Bradbury, S. (2010) 'From racial exclusions to new inclusions: Black and minority ethnic participation in football clubs in the East Midlands of England', International Review of the Sociology of Sport

Bradbury, S. (2011a) 'Racisms, resistance and new youth inclusions: the socio-historical development and shifting focus of black, Asian and minority ethnic football clubs in Leicester in Burdsey, D. (ed.) Race, Ethnicity and Football: Persisting Debates and Emergent Issues Abingdon: Routledge.

Bradbury, S. (2011b) It's not as simple as black and white: challenging racisms in professional football through locally grounded multi-agency collaboration in Long, J. and Spracklen, K. (eds). Sport and Challenges to Racism. Palgrave Macmillan

Bradbury, S., Amara, M., Garcia, B., Bairner, A. (2011) Representation and structural discrimination in football in Europe: The case of minorities and women. Loughborough University 
Bloch, A., \& Levy, C. (Eds.). (1999). Refugees, citizenship, and social policy in Europe.London: Macmillan

Burdsey, D. (2004) 'Obstacle race?: Race, racism and the recruitment of Asian professional footballers' Patterns of Prejudice, Vol 38, No 3, pp 279-30

Burdsey, D. (2006) 'No ball games allowed? A socio-historical examination of the development and social significance of British Asian football clubs', Journal of Ethnic and Migration Studies Vol 32 pp 477496

Burdsey, D. (2007) British Asians and Football: Culture, identity and exclusion. London. Routledge

Bursdey, D. (2009) 'Forgotten Fields? Centralising the experiences of minority ethnic men's football clubs in England', Soccer and Society Vol 10 (6) 704-721

Campbell, P. (2011) What is Rangers resisting now? 'Race', resistance and shifting notions of blackness in local football in Leicester in Burdsey, D. (ed.) Race, Ethnicity and Football: Persisting Debates and Emergent Issues Abingdon: Routledge.

Carrington, B. (2010) Race, Sport and Politics: The sporting black diaspora, Sage, London/Thousand Oaks.

Commission for Racial Equality (2004) Racial Equality in Football. CRE

Council of Europe: European Commission against Racism and Intolerance (2008): ECRI General Policy Recommendation No.12 on Combating racism and racial discrimination in the field of sport - adopted on 19 December 2008 CRI(2009)5 (19 December 2008).

Council of Europe: European Commission Against Racism and Intolerance (2005) Racist Violence in the 15 EU Member States: A Comparative Overview of Findings from the RAXEN Focal Points Reports 20012004

Council of Europe: European Commission Against Racism and Intolerance (2006) Migrants Experience of Racism and Xenophobia in 12 EU Member States (pilot study)

Council of Europe: European Commission against Racism and Intolerance (2008): ECRI General Policy Recommendation No.12 on Combating racism and racial discrimination in the field of sport - adopted on 19 December 2008 CRI(2009)5 (19 December 2008).

Council of Europe: European Commission Against Racism and Intolerance (2010a) Annual Report on ECRI's Activities covering the period From $1^{\text {st }}$ January to $31^{\text {st }}$ December 2009. Council of Europe

Coussey, M. (2002) Tackling Racial Equality: International comparisons. Home Office Research. Development and Statistics Directorate.

Darby, P. (2007) 'African football labour migration to Portugal: colonial and neo-colonial resource', Soccer and Society, 8, 4: 495-509.

European Commission (2008) Discrimination in the European Union: Perceptions, Experiences and Attitudes (Brussels: Special Eurobarometer). 
European Union for Fundamental Rights (2011) Racism, ethnic discrimination and exclusion of migrants and minorities in sport: A comparative overview of the situation in the European Union.

Football Task Force (1998) Eliminating Racism from Football: A report by the football task force submitted to the Minister for Sport. London: The Football Trust.

Giroux, H. (1997) Pedagogy and the Politics of Hope: Theory, culture and schooling: A critical reader. Boulder. Westview

Halm, D. (2005) Turkish immigrants in German Amateur football in Tomlinson, A., and Young, C., German Football: History, Culture and Society. London and New York Routledge. pp 73-92

Hermes, J. (2005) 'Burnt Orange: Television, Football and the Representation of Ethnicity in Television', New Media. Vol 6 (1) 49-69

Hylton, K. (2009) Race and Sport: Critical race theory. Routledge. London and New York

King, C. (2004a) Offside Racism: playing the white man, (Oxford: Berg).

King, C. (2004b) 'Race' and Cultural Identity: playing the race game inside football', Leisure Studies, 23, 19-30.

Lanfranchi, P. \& Taylor, M. (2001) Moving with the Ball: the Migration of Professional Footballers Oxford: Berg.

Long, J. (2000) 'No racism here? A preliminary examination of sporting innocence' Managing Leisure Vol 5, $\mathrm{pp} 121-133$

Long, J. \& Hylton, K. (2002) Shades of White: An Examination of Whiteness in Sport. Leisure Studies, 21, 87-103.

Long, J., Robinson, P., Spracklen, K. (2005) Promoting Racial Equality Within Sports Organisations in Journal of Sport and Social issues. Vol 29 (1) 41-59

Long, J., Hylton, K., Spracklen, K., Ratna, A., Bailey, S. (2009) 'Systematic review of the literature on Black and Minority Ethnic communities in sport and physical recreation' Carnegie Research Institute, Leeds Metropolitan University

Long, J. and Spracklen, K. (eds). (2011) Sport and Challenges to Racism. Palgrave Macmillan

Lusted, J. (2009) 'Playing games with 'race': understanding resistance to 'race' equality initiatives in English local football governance' Soccer and Society, Vol 10, No 6, 722-739

Lusted, J. (2011) Negative equity? Amateurist responses to race equality initiatives in English grass-roots football in Burdsey, D. (ed.) Race, Ethnicity and Football: Persisting Debates and Emergent Issues Abingdon: Routledge. 
Macpherson, W. (1999) 'The Stephen Lawrence Inquiry: report of an Inquiry made by Sir William Macpherson of Cluny', London: Home Office, Cm 4262-I.

Miles R, M. Brown (2003) Racism, Second Edition, London/New York: Routledge

Modood, T. (2005) 'Ethnicity and intergenerational identities and adaptations in Britain: the social context" in Tienda, M. \& Rutter, M. (eds.) Ethnicity and Causal Mechanisms Cambridge: Cambridge University Press.

Niessen, J. (2000). Diversity and cohesion new challenges for the integration of immigrants and minorities (No. ISBN 92-871-4345-5): Council of Europe Publishing,

Pillai, R., Kyambi, S., Nowacka, K., and Sriskandarajah, D. (2006) The Reception and Integration of New Migrant Communities London. Institute of Public Policy Research

Poli, R, (2006) 'Africans' status in the European football players' labour market', Soccer and Society, 7, 2-3: 278-91.

Van Sterkenburg, J., Janssens, J., Rijen, B (Eds) (2005) Football and Racism: An inventory of the problems and solutions in eight West European countries in the framework of the Stand Up Speak Up campaign. Brussels, Muller Institute.

UEFA (2006) Tackling racism in club football. A Guide for Clubs. UEFA 